\title{
Re-significação dos princípios do direito ambiental a partir da ecologia
}

\author{
Reginaldo Pereira* \\ Silvana Terezinha Winckler** \\ Gilza Maria de S. Franco***
}

Sumário: Introdução; 1. O papel da ecologia natural na construção do direito ambiental; 2. Equilíbrio dinâmico; 3. Energia; 4. Evolução e conservação; 5. Serviços ecossistêmicos; Referências.

Resumo: $O$ presente trabalho surge da necessidade de serem estabelecidos parâmetros da ecologia natural para a compreensão dos princípios do direito ambiental. Para tanto evidencia-se inicialmente a importância da ecologia natural para a formação do direito ambiental e o quanto os estudos da ecologia e do direito ambiental deveriam ser informados e dirigidos pela forma interdependente e aninhada de organização assumida pelos sistemas naturais. A seguir realiza-se uma abordagem que procura confrontar os princípios do equilíbrio dinâmico, da energia, da evolução e conservação das espécies e dos serviços ecossistêmicos com os princípios do meio ambiente ecologicamente equilibrado como direito fundamental do ser humano, do desenvolvimento sustentável, da prevenção/precaução e do poluidor pagador.

Palavras-chave: Ecologia natural; Direito ambiental; Sistemas naturais; Dinâmica dos ecossistemas; Princípios do direito ambiental.

\begin{abstract}
The present work appears from the need to establish parameters of the natural ecology for the environmental law principles understanding. For such, it initially becomes evident the importance of natural ecology for the environmental law building and how much the ecology and the environmental law studies should be informed and guided by the interdependent and sheltered organizing way assumed by the natural systems. In sequence, an approach is made in an attempt to confront the dynamic balance principles, the energy principles, the evolution and species maintenance principles, and the ecosystem services as environment principles ecologically balanced as basic right of the human being, of the sustainable development, of the prevention/precaution and of the paying polluting agent.
\end{abstract}

Keywords: Natural ecology; Environmental law; Natural systems; Ecosystems dynamics; Environmental law principles.

\footnotetext{
${ }^{*}$ Me. em Ciências Ambientais - Unochapecó. Professor de Direito Ambiental do Curso de Graduação em Direito - Unochapecó.

** Dra. em Direito - Universidad de Barcelona, U.B., Espanha. Professora do Programa de Pósgradução em Ciências ambientais - Unochapecó.

*** Dra. em Ciências Ambientais - UEM. Professora do Programa de Pós-gradução em Ciências ambientais - Unochapecó.
} 


\section{Introdução}

A incipiência do direito ambiental, quer seja ele considerado como ramo autônomo do direito ou como ciência, confere-lhe determinada fluidez, possibilitando a construção de suas bases teóricas e conceituais. Até mesmo seus princípios já constituídos necessitam ser continuamente conformados para que forneçam a seus estudiosos e operadores meios para garantir o desiderato último deste novo direito.

No presente artigo pretende-se buscar o conteúdo ecológico dos principais princípios que orientam o direito ambiental.

Com o intuito de atingir os objetivos propostos, inicialmente será abordada a relação entre ecologia e direito ambiental, com especial atenção aos cruzamentos necessários entre as duas disciplinas. Posteriormente adentrar-se-á na análise dos princípios que regem o ecossistema e a reverberação destes naqueles que informam o direito ambiental.

\section{0 papel da ecologia natural na construção do direito ambiental}

Em 1866, Haeckel ${ }^{1}$ propôs, em Generelle Morphologie der Organismen, o termo "ecologia" para referir-se à:

[...] ciência das relações dos organismos com o mundo exterior, no qual podemos reconhecer de modo mais amplo os fatores da luta pela existência. Estes são, em parte, de natureza inorgânica; são, como vimos, de maior importância para os organismos forçados a adaptar-se. Entre as condições de existência de natureza inorgânica às quais todo organismo deve submeter-se encontram-se, em primeiro lugar, as características físicas e químicas do hábitat, o clima (luz, temperatura, umidade e eletrização da atmosfera), as características químicas (alimentos não orgânicos), a qualidade da água, a natureza do solo, etc. Sob a denominação de condições de existência, compreendemos o conjunto de relações dos organismos uns com os outros, quer se trate de relações favoráveis ou desfavoráveis. Todo organismo tem amigos e inimigos entre os outros organismos, que favorecem sua existência ou a prejudicam. Os organismos que servem de alimentos aos outros ou que vivem às custas deles como parasitas também devem ser colocados na categoria de condições de existência [...].

\footnotetext{
${ }_{1}^{1}$ Apud DAJOS, Roger. Princípios de ecologia. 5. ed. Trad. Fátima Murad. Porto Alegre: Artmed, 2005, p. V.
} 
A partir do início do século XX, a ecologia passou a ser reconhecida como um campo científico distinto. No início era claramente dividida em linhas taxonômicas: ecologia animal, ecologia vegetal, ecologia aquática, ecologia terrestre. Todavia, com os trabalhos de Frederick E. Clements e de Victor Shelford sobre comunidade biótica, de Raymond Lindeman e G. Evelyn Hutchinson acerca de cadeias alimentares e ciclagem material, e de Edward A. Birge e Chauncy Juday a respeito de lagos inteiros, consolidou-se, a partir de 1930, uma teoria básica da ecologia, denominada "ecologia geral". ${ }^{2}$

Nos últimos anos, impulsionada pela incessante crise ambiental e pela globalização do risco, a ecologia tornou-se uma das ciências mais importantes para o homem, por justamente deter melhores condições de oferecer respostas às questões policontextuais ${ }^{3}$ mais significativas para a continuidade da vida no planeta.

Esta predisposição ao complexo se deve a fatores intrínsecos, tais como o próprio objeto de estudo, mas também a determinantes sócio-ambientais ocorridas nas últimas décadas, que levaram aqueles que se dedicam ao seu estudo a um amadurecimento acerca de seu papel nas sociedades atuais.

A ecologia, além de encontrar-se centrada em três níveis de interesse - o organismo individual, a população (formada por indivíduos da mesma espécie) e a comunidade (conjunto maior ou menor de populações) -, dedica-se também, dentro de seu domínio, ao estudo das rotas de energia e de matéria, "à medida que estas se movem através de elementos vivos e não-vivos de uma categoria posterior de organização, o ecossistema, que compreende a comunidade junto com o seu ambiente físico". ${ }^{4}$

Apesar de ressaltar que à ecologia interessa principalmente o estudo das relações estabelecidas pelos organismos, populações, comunidades, ecossistemas, paisagens, biomas e a biosfera, Odum e Barret ${ }^{5}$ tratam da organização a partir da noção de espectro por entender que este pode ser estendido teoricamente até o infinito nos dois lados, possibilitando o estudo dos sistemas que contenham componentes vivos a partir de qualquer nível de organização sem que se perca de vista a importância de cada nível para os demais:

\footnotetext{
${ }^{2}$ ODUM, Eugene P. Ecologia. Trad. Ricardo Iglesias Rios e Christopher J. Tribe. Rio de Janeiro: Guanabara Koogan, 1988, p. 3.

${ }^{3}$ Cf. ROCHA, Leonel Severo; CARVALHO, Delton Winter de. Policontextularidade e direito ambiental reflexivo. In: Revista Seqüência: estudos jurídicos e políticos - n. 53. Florianópolis: Boiteux, 2006, p. 9-28.

${ }^{4}$ BEGON, Michael; TOWNSEND, Colin R.; HARPER, John L. Ecologia: de indivíduos a ecossistemas. 4. ed. Trad. Adriano Sanches Melo et al. Porto Alegre: Artmed, 2007, p. IX.

${ }^{5}$ ODUM, Eugene; BARRETT, Gary W. Fundamentos de ecologia. Trad. Pégasus Sistemas e Soluções. São Paulo: Thomson Learning, 2007, p. 6.
} 
Uma vez que cada nível no espectro biossistêmico está 'integrado' ou interdependente com os outros níveis, não pode haver linhas divisórias abruptas e rupturas num sentido funcional, nem mesmo entre organismos e população. $\mathrm{O}$ organismo individual, por exemplo, não consegue sobreviver durante muito tempo sem a sua população, do mesmo modo que o órgão não poderia sobreviver muito tempo como unidade autoperpetuante sem o seu organismo. De forma semelhante, a comunidade não consegue existir sem a ciclagem de materiais e o fluxo de energia do ecossistema. ${ }^{6}$

A interconexão é resultado da própria estrutura hierárquica dos sistemas ecológicos, a qual se apresenta aninhada, ou seja, organizada de maneira tal que cada nível acaba sendo composto de grupos de unidades de níveis inferiores, tornando-a, assim, menos rígida e com sinais não tão claros de separação quando confrontada com estruturas organizacionais humanas. ${ }^{7}$

Este atributo do objeto acaba condicionando a ecologia, imprimindo-lhe um caráter complexo, no sentido de ser uma ciência de interface - preocupada com a observação das relações mantidas por cada nível hierárquico com os demais e pelos componentes de cada um isoladamente considerado - e deveria condicionar a forma de operacionalizá-la por aqueles que a estudam, pois, ao contrário de outras ciências que tendem a ramificar-se em processos de especialização, a ecologia por sua própria natureza é uma ciência de sínteses e convergências de saberes díspares, muitos dos quais provenientes de diversas ciências. ${ }^{8}$

A ecologia seria, assim, a ciência que pretende estabelecer a forma como os elementos que compõem determinado ecossistema se organizam, quais as relações que estabelecem com o meio no qual se encontram inseridos, como o influenciam e são por ele influenciados.

Os processos tratados pela ecologia são de vital importância para a construção de um direito apto ao complexo que não reduza as policontextularidades da sociedade atual e que não se auto-referencie através de processos seletivos pautados em uma semântica rígida, com base em discursos jurídicos pré-existentes. ${ }^{9}$ Para tanto, dentre os diversos ramos já estruturados, o direito ambiental é o que apresenta maior predisposição.

O direito ambiental brasileiro, como unidade autônoma com sistematização e princípios próprios, é relativamente recente, não obstante encontrar-se restrições à utilização de recursos naturais já nas Ordenações do Reino de Portugal

\footnotetext{
${ }^{6}$ ODUM, Eugene P. Op. cit., p. 3.

${ }^{7}$ Idem; BARRETT, Gary W. Op. cit., p. 6-7.

${ }^{8}$ MARGALEF, Ramón. Ecologia. Barcelona: Omega, 2005, p. 879.

${ }^{9}$ ROCHA, Leonel Severo; CARVALHO, Delton Winter de. Op. cit., p. 9-28.
} 
que regeram o Brasil desde o descobrimento até a entrada em vigor do Código Civil de 1916.

Prieur ${ }^{10}$ aponta as principais peculiaridades do direito ambiental: i) é um direito de caráter horizontal; ii) recobre os diferentes ramos clássicos do direito (direito civil, administrativo, penal etc.); iii) é um direito de interações, que se encontra disperso nas várias regulamentações; iv) mais do que um novo ramo do direito com seu próprio corpo de regras, tende a penetrar todos os sistemas jurídicos existentes para os orientar num sentido ambientalista; v) é um direito sistematizador, que faz a articulação da legislação, da doutrina e da jurisprudência concernentes aos elementos que integram o meio ambiente; vi) procura evitar o isolamento dos temas ambientais e sua abordagem antagônica; vii) objetiva interligar as diversas ramificações (direito das águas, direito da atmosfera, direito do solo, direito florestal, direito da fauna, direito da biodiversidade etc.) com a argamassa dos instrumentos jurídicos de prevenção e de reparação, de informação, de monitoramento e de participação.

Em decorrência da natureza dos bens tutelados pelo direito ambiental, às características apresentadas pelo autor acrescente-se a de ser interdisciplinar, devendo buscar em outras ciências, dentre as quais a ecologia natural, suas bases conceituais. Para tanto se passa à reelaboração dos princípios do direito ambiental através do funcionamento do ecossistema, delimitando-se a análise nos seguintes princípios: i) equilíbrio dinâmico e ambiente ecologicamente equilibrado como direito fundamental da pessoa humana; ii) energia e desenvolvimento sustentável; iii) evolução/conservação das espécies e prevenção/precaução; iv) serviços ecossistêmicos e poluidor/usuário pagador.

\section{Equilíbrio dinâmico}

O meio natural não se organiza aleatoriamente, já que os fatores abióticos afetam e são afetados pela biocenose. Ainda que se deva resguardar as complexidades, variações e características ímpares de cada ecossistema, determinadas leis lhes são comuns. Estas são denominadas aqui de "princípios", dentre os quais destaca-se, no momento, o que informa que os diversos níveis de organização biológica buscam se manter em equilíbrio.

Os ecossistemas, dadas suas conformações, não são estáticos e apresentam, portanto, um equilíbrio dinâmico, o qual é alcançado pela atuação de mecanismos ou sistemas de controle baseados na homeostase e homeorese.

${ }^{10}$ PRIEUR, Michel. Droit de l'environnement. 5. ed. Paris: Dalloz, 2004, p. 27-58.

Revista Seqüência, no 56, p. 123-150, jun. 2008. 
Homeostase é a capacidade apresentada pelos organismos de manter suas condições internas equilibradas independentemente das alterações do ambiente no qual se encontram inseridos. A homeostase se dá pela atuação de sistemas de retroalimentação negativa e positiva, os quais, a partir de informações obtidas de quimiostatos e termostatos, procurarão, através da atuação de mecanismos internos específicos, restabelecer os sistemas a níveis funcionais desejados.

Estes mecanismos atuarão a partir da medição de um determinado parâmetro, geralmente referente à saída de um dado sistema, o qual, ao ser comparado com a variável ajustada, fará com que os níveis de materiais e energias utilizadas sejam aumentados ou diminuídos, possibilitando desta maneira a correção da distorção percebida.

Não obstante estudos mais recentes realizados por Atlan ${ }^{11}$, Maturana ${ }^{12}$, Monod $^{13}$, Prigogine e Stengers ${ }^{14}$, entre outros, questionarem a pertinência de se estabelecer análises lineares para processos biológicos complexos, em sistemas de controle biológicos de níveis ecológicos situados abaixo da categoria organismos e desta, inclusive, os processos de regulação ocorrem através da homeostase.

A partir da constatação de que a natureza não conta com termostatos e quimiostatos, que irão desencadear uma série de reações em sistemas abertos, que ultrapassam a membrana de um organismo, Odum e Barret ${ }^{15}$ entendem que "a interação entre os ciclos materiais e os fluxos de energia, bem como as retroalimentações de subsistemas em grandes ecossistemas, geram homeorese autocorretiva (rhesis = fluxo ou pulso)".

Nestes níveis de organização, o controle por realimentação apresenta-se mais frouxo, resultando em estados pulsantes em vez de estáveis - ou seja, o equilíbrio apresenta-se desequilibrado, os mecanismos de controle não atuam de forma linear tanto na acepção temporal quanto na espacial. Os componentes dos ecossistemas estão, por outro lado, dispostos de forma difusa, acoplados em redes por meio de sistemas comunicativos e mensageiros que são análogos, embora menos visíveis quando comparados aos sistemas nervosos ou hormonais dos organismos. Tais com-

\footnotetext{
${ }^{11}$ ATLAN, Henri. Entre o cristal e a fumaça: ensaio sobre a organização do ser vivo. Rio de Janeiro: Zahar, 1992.

${ }^{12}$ MATURANA, Humberto. Biologia da autoconsciência. In: CAMPOS PELLANDA, Nize Maria; PELLANDA, Luis Ernesto Cabral (orgs.). Psicanálise hoje: uma revolução do olhar. Petrópolis: Vozes, 1996.

${ }^{13}$ MONOD, Jacques. O acaso e a necessidade: ensaio sobre a filosofia natural da biologia moderna. 4.ed. Petrópolis: Vozes, 1989.

${ }^{14}$ PRIGOGINE, Ilya; STENGERS, Isabelle. A nova aliança: metamorfose da ciência. Trad. Miguel Faria e Maria Joaquina Machado Trincheira. Brasília: Editora Universidade de Brasília, 1991.

${ }^{15}$ ODUM, Eugene P.; BARRETT, Gary W. Op. cit., p. 67.
} 
ponentes procuram manter os sistemas alterando da mesma maneira como alteravam no passado, incluindo desde subsistemas microbianos, responsáveis pela armazenagem e liberação de nutrientes, mecanismos comportamentais, até subsistemas predador-presa, que controlam a densidade populacional, por exemplo. ${ }^{16}$

Algumas considerações mostram-se necessárias, pelo menos para os fins do presente trabalho, quando são confrontados sistemas de controle baseados na homeorese com os homeostáticos.

A primeira está relacionada ao dispêndio energético. A homeostase é custosa, requer trabalho e energia; já a homeorese, necessariamente, não. Para que as condições internas de um indivíduo sejam mantidas dentro de parâmetros regulares, as taxas metabólicas exigidas alterar-se-ão em função do gradiente entre os ambientes externo e interno. ${ }^{17}$

Em redes de ecossistemas, por outro lado, "causas de baixa energia produzindo efeitos de alta energia são onipresentes [...]"18. Os autores ilustram a assertiva:

Insetos minúsculos, conhecidos como Hymenoptera parasita, representam uma porção muito pequena (geralmente menos de $0,1 \%$ ) do metabolismo total da comunidade de um ecossistema de campo, porém eles podem ter um grande efeito controlador no fluxo de energia primária total (produção) por conta do impacto de seu parasitismo sobre insetos herbívoros.

Outro aspecto a ser considerado está relacionado aos pontos de viragem que determinarão o equilíbrio de um sistema. Enquanto os organismos apresentam pontos fixos, os ecossistemas, além de possuírem "mais de um estado de equilíbrio, freqüentemente retornam a um equilíbrio diferente após uma perturbação". ${ }^{19}$

Tais características condicionam a atuação de sistemas homeostáticos, cuja eficiência dependerá do nível de perturbação a que é submetido e, em sistemas de regulagem frouxa - homeorese - possibilitam que os ecossistemas alterem-se no tempo ou se auto-organizem a partir de novas feições em processos de sucessão ecológica quando submetidos a perturbações estocásticas, pois, como revela Margalef:

Por outra parte, a organização do ecossistema é aberta, heterogênea e submetida a inúmeras alterações não previsíveis provenientes da própria organização do

\footnotetext{
${ }^{16}$ Ibidem, p. 68-69.

${ }^{17}$ RICKLEFS, Robert E. A economia da natureza. 5. ed. Trad. Cecília Bueno, Pedro P. de Lima-eSilva e Patrícia Moussinho. Rio de Janeiro: Guanabara Koogan, 2003, p. 61.

${ }^{18}$ ODUM, Eugene P.; BARRETT, Gary W. Fundamentos de ecologia. Op. cit., p. 69.

${ }^{19}$ Ibidem, p. 69.
} 
ecossistema. Por todas estas razões, as mudanças que experimentam através do tempo resultam de uma união indissolúvel entre o aleatório e o determinado; tratase de um processo de auto-organização perturbado de maneira corriqueira por acontecimentos imprevisíveis e, com freqüência, irreproduzíveis. ${ }^{20}$

Além dos sistemas de regulação, que determinarão o equilíbrio dinâmico nos ecossistemas, fatores como a resistência, a resiliência e a redundância atuam para que estes se mantenham estáveis.

A estabilidade de um ecossistema é definida em função da sua habilidade em resistir à mudança, mantendo sua estrutura e função intactas quando confrontado por uma perturbação, ou em razão da capacidade de um sistema em se recuperar quando é rompido por alguma perturbação. A resistência e a resiliência são faces diferenciadas da estabilidade que não se confundem. Além do quê, um número cada vez maior de evidências tem demonstrado que estes dois tipos de estabilidade podem, em diversas situações, ser mutuamente excludentes. ${ }^{21}$

Uma floresta de sequóias sempre-verdes na Califórnia é bastante resistente ao fogo, mas caso venha a ser destruída por queimadas, recuperar-se-á muito lentamente ou talvez nunca. Tal ecossistema apresenta alto grau de resistência e baixa resiliência. Em contrapartida, a vegetação de chaparral da Califórnia se queima com facilidade e se recupera rapidamente (baixa resistência e alta resiliência). Como regra geral, pode-se esperar que ecossistemas em locais físicos propícios apresentem mais estabilidade de resistência e baixa capacidade de resiliência. O contrário vale para ecossistemas localizados em ambientes físicos incertos. ${ }^{22}$

A redundância possibilita que funções de um determinado sistema permaneçam estáveis não por controles cibernéticos, mas pela compensação entre diferentes componentes funcionais de um sistema, como, v.g., ocorre em ecossistemas que apresentam várias espécies de autótrofos com faixas operacionais flutuantes em função da temperatura. Assim, independente da faixa de temperatura a taxa de fotossíntese da comunidade permanecerá estável. ${ }^{23}$

Em resumo, a estabilidade de um ecossistema é resultado da atuação em rede de sistemas de regulação homeostáticos e difusos, da resistência e da resiliência apresentadas pelo ecossistema e, ainda, de mecanismos de compensação entre seus componentes, para que as taxas funcionais permaneçam estáveis independentemente de alterações externas. Todos estes fatores são afetados e tendem a alterarse em função do espaço físico, do local onde a biocenose vive (biótopo) e do tempo

\footnotetext{
${ }^{20}$ MARGALEF, Ramón. Op. cit., p. 680.

${ }^{21}$ ODUM, Eugene P. Op. cit., p. 32.

${ }^{22}$ Idem, BARRET Gary W. Op. cit., p. 70.

${ }^{23}$ Idem. Op. cit., p. 31.
} 
- já que a evolução dos indivíduos, das populações, das comunidades e dos ecossistemas deve ser também considerada.

O equilíbrio dinâmico, dado ser um dos principais atributos dos ecossistemas, condiciona a interpretação de todos os princípios orientadores do direito ambiental brasileiro, em especial aquele que informa ser o ambiente ecologicamente equilibrado direito fundamental do ser humano.

O legislador constituinte de 1988 elevou o meio ambiente à categoria de direito fundamental indisponível, imprescritível e irrenunciável, cujos titulares são todos que compõem as presentes gerações; logo, trata-se de bem difuso - no sentido de pertencer a todos e a ninguém ao mesmo tempo, ou no sentido de ser um bem ou interesse que difere do interesse público e do privado, constituindo um terceiro gênero. Sua compreensão só é possível a partir da constatação de que se trata de um direito ínsito das sociedades que massificam a produção, o consumo, a informação, a publicidade e o risco, sendo bem essencial à sadia qualidade de vida, conforme preconizam o princípio 1 da Declaração de Estocolmo Sobre o Ambiente Humano e o princípio 1 da Declaração do Rio de Janeiro de 1992 Sobre Meio Ambiente e Desenvolvimento.

Bello Filho ${ }^{24}$ considera ser o direito ao ambiente ecologicamente equilibrado um direito fundamental nas dimensões real, teórica e positiva, pois "desde 1988, com a previsão normativa deste direito fundamental por intermédio do art. 225 da $\mathrm{CF}$, não há mais dúvida sobre seu posicionamento enquanto tal [...]”.

Por ser fundamental é de aplicabilidade imediata. Sem depender de qualquer regulamentação, tal direito vincula o Estado à defesa e preservação do meio ambiente - dever positivo, representado por verdadeiras obrigações de fazer - e impõelhe restrições à atuação como agente empreendedor - dever negativo, representado por obrigações de não fazer. Ao mesmo tempo, a pertença à terceira dimensão de direitos, pautada na fraternidade, importa à coletividade a atribuição de defendêlo e preservá-lo.

Estreme de dúvidas resta, assim, o meio ambiente como direito fundamental de todos. Duas questões, no entanto, merecem ser problematizadas, não porque sejam objeto de incessantes e acalorados debates, mas sobretudo em virtude do reticente silêncio que as circunda e que pode denotar falta de compreensão em relação aos seus alcances.

\footnotetext{
${ }^{24}$ BELLO FILHO, Ney de Barros. Teoria do direito e ecologia: apontamentos para um direito ambiental no século XXI. In: FERREIRA, Helini Sivini; LEITE, José Rubens Morato (orgs.). Estado de direito ambiental: tendências: aspectos constitucionais e diagnósticos. Rio de Janeiro: Forense, 2004, p. 103.
} 
A primeira está relacionada ao conteúdo do pronome indefinido "todos" que abre o artigo 225 da Constituição da República Federativa do Brasil de 1988; a segunda, ao adjetivo "ecologicamente equilibrado" atribuído pelo constituinte ao meio ambiente.

A acepção jurídico-ambiental de "todos" altera-se em função da ideologia que informa sua elaboração intelectual.

Duarte ${ }^{25}$ enumera três posições divergentes em relação à percepção da problemática ambiental na sociedade moderna: i) na primeira há um total descompromisso com a questão ambiental. Nesta estariam incluídos os que por entenderem a irrelevância dos problemas ambientais apregoam que o direito não deveria deles se ocupar; ii) na segunda encontram-se aqueles que percebem a proteção do meio ambiente como parte da tutela dos direitos dos seres humanos; iii) na terceira situam-se os ecofundamentalistas, ou seja, aqueles que, segundo a autora, amparados em "uma inconseqüente, imatura, utópica, e romântica visão da questão ambiental" parecem "ignorar o complexo estágio econômico, social e político em que se encontra a sociedade, em que a proteção e defesa ambiental não pode significar a estagnação das atividades sociais, econômicas e políticas".

Poder-se-ia, então, atrelar a noção de "todos" a três perspectivas: antropocêntrica clássica, biocêntrica e antropocêntrica alargada.

$\mathrm{O}$ antropocentrismo clássico está centrado no homem e é fruto, em um primeiro momento, da história da modernidade, da necessidade de superar-se o teocentrismo até então vigente. Com a possibilidade de dominação da natureza através da razão instrumental, o homem "elevou-se" a patamares jamais atingidos.

Na visão antropocêntrica clássica, "todos" somente pode ser tomado no sentido de todas as pessoas, todos os seres humanos, toda a gente. Este entendimento acerca da posição superior do homem em relação à natureza acaba inviabilizando a proteção das demais espécies senão em virtude do homem.

O biocentrismo é diametralmente oposto ao antropocentrismo clássico. Segundo esta corrente filosófica, todas as formas de vida detêm a mesma importância, não havendo distinção hierárquica entre a humanidade e os demais componentes da ecosfera que passariam de objeto a sujeitos de direito.

O biocentrismo é relacionado à ecologia profunda, a qual é alimentada por um impulso romântico extraordinário de retorno à natureza. O principal problema da concepção biocêntrica é a supressão que promove do elemento cultural do meio

\footnotetext{
${ }^{25}$ DUARTE, Marise Costa de Souza. As novas exigências do direito ambiental. In: LEITE, José Rubens Morato; BELLO FILHO, Ney de Barros (orgs.). Direito ambiental contemporâneo. Barueri: Manole, 2004, p. 515.
} 
ambiente, pois ao tornar ilimitado o reino do natural, a pretexto, nomeadamente, de uma poderosa mitologização da vida, suprime-se por completo a parte do cultural. ${ }^{26}$

Em relação a um de seus efeitos em especial, o biocentrismo promove, tal qual o antropocentrismo clássico, de acordo com o citado autor, a dicotomia homem/ natureza e, por esta razão, a noção de "todos" poderia ser tomada a partir da exclusão do ser humano.

As limitações apresentadas pelas teorias informadas pelo antropocentrismo e biocentrismo possibilitaram o surgimento de uma terceira corrente.

A partir de uma noção antropocêntrica alargada, "todos" seriam todos os seres humanos, desta e das futuras gerações, e os demais elementos bióticos e abióticos que compõem todos os ecossistemas, tomados de per si e/ou integrados.

$\mathrm{O}$ antropocentrismo alargado busca estabelecer-se entre o antropocentrismo clássico e o biocentrismo para, desta forma, tratar do meio ambiente a partir de uma perspectiva que viabilize a proteção da sanidade ambiental para a sadia qualidade da vida em todas as suas formas, sejam humanas ou não.

Leite $^{27}$, um dos mais expressivos articulistas do conceito no Brasil, observa inicialmente que o antropocentrismo alargado busca superar o clássico sem adentrar, contudo, nos postulados do biocentrismo, e é, na verdade, fruto de uma evolução da visão antropocêntrica, operacionalizada como resposta às críticas dos biocentristas sobre uma eventual supremacia do homem sobre a natureza.

Para o autor, princípios inseridos no ordenamento jurídico brasileiro a partir da promulgação da $\mathrm{CF} / 88$, como o do desenvolvimento sustentável e o da eqüidade intergeracional, "exigem restrições das atividades econômicas, considerando as necessidades da preservação do ecossistema e, assim, uma maior 'reverência pela natureza' e distanciamento da visão antropocêntrica radical", impondo "uma verdadeira solidariedade e comunhão de interesses entre o homem e a natureza, como condição imprescindível para assegurar o futuro de ambos e dependente de forma insofismável da ação do primeiro, como verdadeiro guardião da biosfera" ${ }^{28}$

$\mathrm{O}$ antropocentrismo alargado visa, ainda, superar a noção economicêntrica mediante a qual a preservação dos elementos dos ecossistemas encontra-se adstrita ao valor destes como recursos naturais, passíveis de apropriação econômica pelo homem, e que devem ser preservados em função única e exclusiva desta qualidade.

${ }^{26} \mathrm{OST}$, François. A natureza à margem da lei: a ecologia à prova do direito. Lisboa: Instituto Piaget, 1997, p. 13-15.

${ }^{27}$ LEITE, José Rubens Morato. Dano ambiental: do individual ao coletivo extrapatrimonial. São Paulo: Revista dos Tribunais, 2000, p. 72-96.

${ }^{28}$ LEITE, José Rubens Morato; AYALA, Patryck de Araújo. Novas tendências e possibilidades do direito ambiental no Brasil. In: WOLKMER, Antônio Carlos; LEITE, José Rubens Morato (orgs.).

Os novos direitos no Brasil: natureza e perspectivas. São Paulo: Saraiva, 2003, p. 212.

Revista Seqüência, no 56, p. 123-150, jun. 2008. 
Através de uma interpretação sistemática dos dispositivos constitucionais relacionados ao meio ambiente, mostra-se viável promover a defesa de sua proteção por seu valor intrínseco, quer em função dos princípios, direitos, deveres e meios operacionais explicitados pelo legislador no texto constitucional - direitos e deveres genéricos constantes no caput do art. 225; deveres especiais inseridos no $\S 1^{\circ}$ do referido artigo; princípios específicos explícitos como, por exemplo, o da função ecológica da propriedade rural (artigo 186, II) e do poluidor-pagador (artigo 225, §§ $2^{\circ}$ e $3^{\circ}$ ); instrumentos de execução como o estudo de impacto ambiental (artigo $225, \S 1^{\circ}$, IV) e a ação civil pública (artigo 129 , III, e $\S 1^{\circ}$ ) - ou em função da proteção outorgada a determinados biomas de grande valor ecológico - Mata Atlântica, Pantanal, Floresta Amazônica, Serra do Mar e Zona Costeira (artigo 225, § $4^{\circ}$ ) ou, ainda, por força de princípios genéricos implícitos que emanam da interpretação do sistema constitucional de proteção ao meio ambiente, tais como o dever genérico de não degradar e dos princípios da primariedade do meio ambiente e da explorabilidade limitada da propriedade. ${ }^{29}$

No nível infraconstitucional, o artigo $3^{\circ}$, I, da Lei $n^{\circ} 6.938 / 81$ define meio ambiente como o "conjunto de condições, leis, influências e interações de ordem física, química e biológica, que permite, abriga e rege a vida em todas as suas formas". Como se verifica, o conceito adotado na lei é alargado, compreendendo todas as formas de vida e não somente a humana, sem hierarquia.

Por outro lado, a defesa do meio ambiente fundada na necessidade da manutenção do equilíbrio ecológico como valor que deva ser garantido não somente pela importância cultural e econômica que apresenta avultou-se com a percepção dos efeitos oriundos da sociedade de risco global sobre grandes biomas e processos ecológicos de regulação - como, por exemplo, o responsável pela manutenção da temperatura global em níveis adequados.

Disto resulta a necessária atualização dos princípios ambientais, quer sejam estes constitucionais ou não, sob pena de ineficácia ao longo do tempo. É neste ponto que se pretende inserir a abordagem realizada no presente trabalho, justificada pelo agravamento e mundialização da crise ambiental, por um lado, e pelo avanço da ecologia natural, pela incorporação de novos conceitos e formas mais holísticas de abordagem e, ainda, pela crescente noção de que os problemas ambientais devem ser tratados de maneira multidisciplinar, privilegiando a necessária relação ho$\mathrm{mem} /$ natureza, por outro.

As constatações acima, além de alargarem o alcance do termo "todos", que necessariamente passa a englobar todos os elementos que compõem a ecosfera, de

\footnotetext{
${ }^{29}$ BENJAMIN, Antônio Herman. Direito constitucional ambiental brasileiro. In: CANOTILHO, José Joaquim Gomes; LEITE, José Rubens Morato (orgs.). Direito constitucional ambiental brasileiro. Rio de Janeiro: Saraiva, 2007. p. 84-97.
} 
natureza biótica e abiótica - o que, na verdade, não constitui novidade alguma condiciona a interpretação da expressão "ecologicamente equilibrado", conferida ao meio ambiente.

A dinamicidade do equilíbrio natural, fruto de regulações baseadas na homeostase e na homeorese - que, juntamente com características próprias de cada ecossistema, tais como a resistência, a resiliência e a redundância, determinam sua estabilidade -, faz com que a expressão "todos", muitas vezes relegada a um segundo plano em processos interpretativos, adquira importância na medida em que todos os indivíduos e componentes de um ecossistema são significativos para que este se mantenha estável.

Dessa forma, ao sentir de Benjamin ${ }^{30}$ - "Na verdade, o equilíbrio ecológico, no sentido utilizado pela Constituição, antes de ser estático, é um sistema dinâmico" - acrescente-se: e que, ao mesmo tempo, encontra-se inexoravelmente atrelado à atuação de todos os seus elementos, não podendo um prescindir do outro. Esta percepção se impõe ao atual intérprete, ao estabelecer o conteúdo do princípio do meio ambiente ecologicamente equilibrado como direito fundamental.

\section{Energia}

A partir do início do século XX, uma série de novos conceitos possibilitou abordagens inéditas sobre o funcionamento dos ecossistemas. Um deles foi desenvolvido na década de 1920 pelo ecólogo inglês Charles Elton, o qual argumentava que, além de sofrer de tolerâncias semelhantes aos fatores físicos do ambiente, os organismos ocorrentes em um mesmo local interagem entre si, estabelecendo relações alimentares sistemáticas, denominadas "teia alimentar". Mais tarde, durante a década de 1930, A. G. Tansley formulou o conceito de ecossistema - formado pela conjunção dos animais e plantas e dos fatores físicos de seu entorno - e o considerou a unidade fundamental de organização ecológica. "Tansley visualizou os componentes biológicos e físicos da Natureza juntos, unificados pela dependência dos animais e das plantas em seus ambientes físicos e por suas contribuições para a manutenção das condições e composição do mundo físico". ${ }^{31}$

Em 1942, Raymond Lindeman publica um artigo intitulado The trophic dynamic aspect of ecology, no qual descreve o funcionamento do lago Cedar Bog. Lindeman teve a idéia de converter as biomassas de diversas espécies em seu equivalente energético, expondo as noções clássicas de produtividade primária e secundária,

\footnotetext{
${ }^{30}$ Ibidem, p. 107.

${ }^{31}$ RICKLEFS, Robert E. Op. cit., p. 118.
} 
transferência de energia, rendimento e reciclagem de elementos. Em 1953, Eugene P. Odum, no livro Fundamentos de ecologia, enfatizou o metabolismo dos ecossistemas, os fluxos de energia e a produtividade. A utilização de unidades básicas de medição de energia - unidades de energia potencial e unidades de potência ou taxa - possibilitou a comparação de indivíduos, populações, níveis tróficos e ecossistemas diferentes em relação ao rendimento energético. ${ }^{32}$

Comumente definida como a capacidade de gerar trabalho, a energia em ecossistemas obedece a dois princípios termodinâmicos - o da conservação e o da entropia - e está relacionada à capacidade de produção de biomassa que servirá de alimento para os diversos indivíduos inseridos em níveis tróficos - produtores, consumidores e decompositores - e que compõem uma teia alimentar.

A primeira lei da termodinâmica, conhecida como lei da conservação da energia, estabelece a possibilidade de a energia transformar-se de um tipo em outro, mas não de ser criada nem destruída. Praticamente toda a energia que a superfície da Terra recebe é oriunda do Sol. As plantas, algas e algumas bactérias captam a energia luminosa e a transformam em energia de ligações químicas nos carboidratos, através da fotossíntese que une quimicamente dois compostos inorgânicos comuns, o dióxido de carbono $\left(\mathrm{CO}_{2}\right)$ e a água $\left(\mathrm{H}_{2} \mathrm{O}\right)$ para formar o açúcar glicose $\left(\mathrm{C}_{6} \mathrm{H}_{12} \mathrm{O}_{6}\right)$, sendo liberado desta reação o oxigênio $\left(\mathrm{O}_{2}\right)$.

Os herbívoros (consumidores primários) se alimentam das espécies fotossintéticas. Os carnívoros (consumidores secundários ou predadores) alimentam-se de outros animais. Os carnívoros primários (como as raposas) alimentam-se de herbívoros (como os coelhos), já os carnívoros secundários (como as cobras) alimentam-se de outros carnívoros (como os sapos) e também de herbívoros. Alguns carnívoros combinam a predação direta com a necrofagia. Os onívoros incluem em sua dieta uma proporção considerável de plantas. Os decompositores se alimentam de plantas mortas, tecidos animais e detritos, destruindo tecidos complexos e moléculas orgânicas, liberando minerais como nitrogênio e fósforo, que voltam ao ambiente onde foram retirados pelas plantas e algas. Os fungos e as bactérias são os decompositores mais importantes, mas muitas outras espécies exercem a mesma função, tais como os urubus, besouros de estrume e vermes. ${ }^{33}$

Se, por um lado, matéria e energia seguem o mesmo caminho dentro da teia alimentar, por outro a matéria obedece ao princípio do retorno, através de ciclos biogeoquímicos, enquanto que a energia segue em um fluxo contínuo, sendo dissipada e irradiada ao longo da biosfera. A dissipação de energia na biosfera pode ser explicada a partir da segunda lei da termodinâmica.

${ }^{32}$ DAJOS, Roger. Op. cit., p. 266.

${ }^{33}$ PRIMACK, Richard B.; RODRIGUES, Efraim. Biologia da conservação. Londrina: E. Rodrigues, 2001, p. 21-22. 
Em 1865, alguns anos após Darwin publicar A origem das espécies, o físico alemão RudolfClauisius formula a segunda lei da termodinâmica, vinculada à entropia (derivada de entropé, vocábulo utilizado pelos gregos para significar mudança, evolução, volta). De acordo com a segunda lei da termodinâmica, a mudança de entropia pode ser decomposta em duas partes: i) o fluxo de entropia, que corresponde às trocas com o mundo externo; e ii) a produção de entropia, referente aos processos irreversíveis de degradação que acontecem dentro do sistema e que necessariamente será nula ou positiva, resultando daí que a entropia em um sistema isolado aumenta até que este alcance o equilíbrio. ${ }^{34}$

Dentre as diversas elaborações realizadas acerca da lei da entropia, Odum e Barret ${ }^{35}$ ressaltam duas: i) a primeira está relacionada à dissipação em processos de transformação de energia: "[...] nenhum processo envolvendo transformação de energia irá ocorrer espontaneamente, a menos que haja a degradação da energia de uma forma concentrada para uma forma dispersa"; ii) a segunda se vincula à perda de eficiência energética em função da dissipação de energia, ou seja, da energia gasta na transformação da energia $(e n=$ "em" + trope = "transformação"): "[...] nenhuma transformação espontânea de energia (como a luz solar, por exemplo) em energia potencial (protoplasma, por exemplo) é $100 \%$ eficiente, porque alguma parte da energia sempre será dispersada sob a forma de energia térmica não disponível".

A organização dos seres vivos se dá, assim, a custa de uma constante dissipação de energia. Schrödinger ${ }^{36}$ enfatiza que a conservação e o equilíbrio dos seres vivos são mantidos por uma degradação equivalente de energia, alimentando-se de entropia negativa: "Um organismo vivo pode manter-se afastado da morte, isto é, vivo, extraindo, incessantemente, do respectivo meio ambiente entropia negativa [...]. Um organismo alimenta-se de entropia negativa".

Não obstante ser a energia solar responsável pela produção de calor, evaporação, precipitação, vento e outros fenômenos responsáveis pela criação de um ambiente favorável para a vida na terra, os dados fornecidos pelo autor acima indicam uma limitação na produção natural de energia. Tal fator, por um lado, condiciona o crescimento das espécies que compõem o ambiente natural, já que nenhuma pode obter energia de outra fonte que não as inseridas na rede trófica. Por outro impulsiona as espécies, inclusive a humana, a abastecer-se de energia em fontes subsidiárias ou auxiliares, que permitem altas taxas de produção em ecossistemas naturais e agrícolas.

${ }^{34}$ PRIGOGINE, Ilya; STENGERS, Isabelle. Op. cit., p. 27.

${ }^{35}$ ODUM, Eugene P.; BARRETT, Gary W. Op. cit., p.78.

${ }^{36}$ SCHRÖDINGER, Erwin. O que é a vida? 2. ed. Trad. M. L. Pinheiro. Lisboa: Fragmentos, 1989, p. 73-74.

Revista Seqüência, nº 56, p. 123-150, jun. 2008. 
Subsídio de energia ou fluxo de energia auxiliar é qualquer energia secundária que suplemente a solar e permita e potencialize a armazenagem e repasse de fotossintato pelas plantas, tais como o vento e a chuva em uma floresta úmida, a energia de marés em um estuário e os combustíveis fósseis utilizados no cultivo agrícola. Tais elementos físicos ou químicos são exemplos de subsídios de energia, pois aumentam a produção das plantas e beneficiam animais adaptados a fazer uso da energia auxiliar. ${ }^{37}$

Por ter obtido sucesso na inserção de circuitos auxiliares de energia para a produção de alimentos, o homem tem conseguido suplantar as limitações impostas pelo meio natural e este fator é determinante para a manutenção da vida - humana - nos padrões atuais. Tal raciocínio é, do mesmo modo, válido para qualquer outra atividade de cunho antrópico.

Todavia, ao contrário da energia solar - que é naturalmente dissipada - a obtida de fontes subsidiárias, principalmente as desenvolvidas pelo homem, quando analisadas a partir do segundo princípio da termodinâmica, apresentam uma série de limitações relacionadas à eficiência e à sustentabilidade.

Uma destas está ligada à capacidade de assimilação de energia pelos sistemas, sejam naturais ou culturais. Odum e Barret ${ }^{38}$ demonstram que a energia subsidiária presente na entrada de um sistema pode aumentar a sua produtividade ou desempenho até o ponto em que ele atinge a saturação, ou seja, a capacidade de dissipar energia. A partir daí seu rendimento irá declinar.

O gradiente subsídio-estresse faz com que algo a princípio bom torne-se tão - ou até mais - danoso em demasia quanto se ausente. Além do que, "conforme o subsídio começa a se transformar em estresse, a variância aumenta, [...] conseqüentemente o sistema começa a oscilar fora de controle até ser substituído por outro sistema mais tolerante à perturbação - ou até que a vida não seja mais viável". ${ }^{39}$

Os limites ecológicos apresentados, juntamente com aportes teóricos provenientes da economia, são determinantes para a interpretação do princípio do desenvolvimento sustentável.

Barral e Ferreira ${ }^{40}$ sustentam que a combinação das duas leis da termodinâmica conduz à noção de que, apesar de a energia ser constante, de acordo com a primeira

\footnotetext{
${ }^{37}$ ODUM, Eugene P.; BARRETT, Gary W. Op. cit., p. 91.

${ }^{38}$ Ibidem, p. 93-94.

${ }^{39}$ Ibidem, p. 93.

${ }^{40}$ BARRAL, Welber; FERREIRA, Gustavo Assed. Direito ambiental e desenvolvimento. In: BARRAL, Welber; PIMENTEL, Luiz Otávio (orgs.). Direito ambiental e desenvolvimento. Florianópolis: Boiteux, 2006, p. 16.
} 
lei, continuamente, com ou sem a atuação do homem, ela passa da disponibilidade à indisponibilidade, conforme enuncia a segunda lei, sendo este processo irreversível. A atuação humana, principalmente a relacionada à produção econômica, acelera a degradação entrópica, pois o homem, ao contrário das demais espécies, processa praticamente tudo que consome e qualquer processo pressupõe gasto energético.

Para possibilitar o cruzamento de ecologia e economia, em relação ao dispêndio energético em sistemas, sejam ecológicos ou econômicos, além dos limites ecológicos, faz-se necessária a abordagem de dois conceitos-chave para a questão: $\mathrm{o}$ de geossistema e o da capacidade de suporte.

Geossistema seria uma síntese geográfica integradora do natural ao humano. ${ }^{41}$ Este conceito leva em consideração a atuação da população humana em determinado espaço, agregando natureza e cultura.

Capacidade de suporte, para Ricklefs ${ }^{42}$, é o "número de indivíduos numa população que os recursos de um habitat podem sustentar".

Aplicando-se o conceito de capacidade de suporte aos geossistemas, ou seja, considerando-se também a população humana e a sua relação com determinado ecossistema, obtém-se, no campo da economia ecológica, a noção de desenvolvimento sustentável. ${ }^{43}$

Os Princípios 1, 2 e 3 da Declaração do Rio de Janeiro sobre Meio Ambiente e Desenvolvimento fornecem os elementos que integram o conceito de desenvolvimento sustentável. O primeiro preconiza que os seres humanos estão no centro das preocupações com o desenvolvimento sustentável, tendo direito a uma vida saudável e produtiva, em harmonia com a natureza; o terceiro princípio apregoa que o desenvolvimento sustentável será atingido quando propiciar às presentes e às futuras gerações o atendimento eqüitativo de suas necessidades; no Princípio 2 é garantido aos Estados o direito soberano de explorar seus próprios recursos segundo suas próprias políticas de meio ambiente e desenvolvimento.

Os principais objetivos buscados pelas políticas ambientais e desenvolvimentistas derivadas do conceito de desenvolvimento sustentável, de acordo com Pierri ${ }^{44}$, são: i) retomar o crescimento; ii) mudar a qualidade do desenvolvimento; iii) atender às

\footnotetext{
${ }^{41}$ Ibidem, p. 19.

${ }^{42}$ RICKLEFS, Robert E. Op. cit., p. 481.

${ }^{43}$ MONTIBELLER FILHO, Gilberto. O mito do desenvolvimento sustentável: meio ambiente e custos sociais no moderno sistema produtor de mercadorias. 2. ed. rev. Florianópolis: UFSC, 2004, p. 124.

${ }^{44}$ PIERRI, Naína. El proceso histórico y teórico que conduce a la propuesta del desarrollo sutentable. In: PIERRI, Naína; FOLADORI, Guilhermo (orgs.). ¿Sustentabilidad?: Desacuerdos sobre el desarrollo sustentable. Montevidéu: Trabajo y Capital, 2001, p. 59.
} 
necessidades básicas de emprego, alimentação, energia, água e saneamento; iv) manter um nível populacional sustentável; v) conservar e melhorar a base dos recursos; vi) reorientar a tecnologia e administrar o risco; e vii) incluir o meio ambiente e a economia no processo de tomada de decisões.

Observe-se que apesar de estar alicerçado na sustentabilidade, ou seja, na capacidade de suporte ótima, o conceito de desenvolvimento sustentável em hipótese alguma desvincula-se da noção desenvolvimentista que embalou e embala os sonhos da modernidade, fato este que, segundo alguns autores, limita e até impossibilita sua efetiva aplicação. Além dessa, outras críticas merecem ser destacadas. Ponto crucial, encontradiço na interface ecologia/economia, pautado em parâmetros ecossistêmicos e geossistêmicos - que possibilitariam a implementação de um desenvolvimento que garantisse às atuais e às futuras gerações um meio ambiente ecologicamente equilibrado - é a diferenciação entre consumo endossomático e exossomático.

O consumo endossomático é aquele destinado a suprir as necessidades básicas ou naturais de um indivíduo, sendo o único tipo registrado em ecossistemas, é o consumo interno. O consumo exossomático, por outro lado, é o consumo externo, o consumo extra, definido em função de valores culturais e sociais de um indivíduo ou comunidade. ${ }^{45}$

Por maiores que sejam as diferenças econômicas entre dois humanos adultos, eles despenderão quantidades semelhantes de energia endossomática. Por outro lado, o gasto exossomático de energia altera-se consideravelmente em função de fatores culturais, econômicos, geográficos, políticos, sociais etc.

E como "a maioria dos humanos tem dificuldade em determinar quando o bastante é suficiente" 46 , pois o ser humano "carece de instruções genéticas que determinem seu uso exossomático de energia" ${ }^{47}$, força reconhecer a existência de limites ao desenvolvimento sustentável.

Foladori ${ }^{48}$ sustenta que os principais limites ao desenvolvimento sustentável não são, como a princípio possam aparentar, de natureza física, pautada na noção errônea e facilmente perceptível de que se trata de equacionar necessidades infinitas e recursos finitos. Para o autor o problema é, antes de tudo, sociológico, de conflito de classes e de suas representações mentais que impedem a discussão

\footnotetext{
${ }^{45}$ BARRAL, Welber; FERREIRA, Gustavo Assed. Op. cit., p. 20.

${ }^{46}$ ODUM, Eugene P.; BARRETT, Gary W. Op. cit., p. 94.

${ }^{47}$ ALIER, Joan Martinez; JUSMET, Jordi Roca. Economia ecológica y política ambiental. 2. ed. México: Fondo de Cultura Econômica, 2001, p. 23.

${ }^{48}$ FOLADORI, Guilhermo. Limites do desenvolvimento sustentável. Campinas: Unicamp; São Paulo: Imprensa Oficial, 2001, p. 119-133.
} 
acerca da maneira capitalista de produção e centralizam o debate em torno das formas de correção dos efeitos negativos que a produção de bens acarreta à sociedade. Além do quê, o próprio planeta enquanto local propício à vida é finito e, se for considerado que atualmente existe apenas $1 \%$ do total de espécies que algum dia povoou a Terra, o problema dos limites passa a ser de velocidade de utilização.

O problema não é mais determinar se um bem ambiental findará e sim quando. Antes ou depois da espécie humana não mais existir? Antes ou depois de ser desenvolvida uma nova tecnologia ou bem substituto?

Por esta ótica, nos termos em que a questão é posta pelos defensores do desenvolvimento sustentável, a noção de capacidade de suporte é desviada de um ponto ótimo, ecologicamente dado - no qual a energia, além de atender às necessidades de respiração de determinado sistema, é disponibilizada para outros níveis de organização sistêmica - e passa a ser relacionada a critérios temporais como, por exemplo, a estimação de esgotamento de um determinado recurso natural e de sua substituição por outro que possa atender com eficiência às necessidades ditadas por padrões exossomáticos de consumo sem que estes sejam problematizados à luz das leis que determinam o comportamento da energia nos ecossistemas e nos geossistemas.

\section{Evolução e conservação}

Os conceitos e aspectos relacionados à evolução das espécies e conservação biológica geralmente são objeto de tratamentos distintos pelos ecólogos. Propõe-se no presente trabalho a análise conjunta, já que se encontram inter-relacionados e podem ser utilizados como indicadores para a aplicação dos princípios da prevenção e da precaução quando abordados em função dos limites observados em vista da necessidade de se estabelecer garantias para que espécies e comunidades atingidas por empreendimentos humanos tenham a possibilidade de se manter geneticamente viáveis.

Diversos aportes demonstram-se viáveis em relação à evolução das espécies. No presente trabalho faz-se a opção pela abordagem das interações das teorias evolucionistas com a conservação das espécies, ou seja, com a manutenção de padrões que garantam a variabilidade de organismos vivos de todas as origens (Lei $\mathrm{n}^{\circ} 9.985 / 00$, art. $2^{\circ}$, III).

A utilização indiscriminada dos bens ambientais na sociedade de risco global tem causado uma perda significativa da diversidade biológica. As principais causas de extinção de espécies oriundas de atividades antrópicas são a destruição, a fragmentação de ecossistemas, a degradação do habitat (incluindo a causada pela polui- 
ção), a superexploração das espécies para uso humano, a introdução de espécies exóticas e o aumento de ocorrência de doenças. ${ }^{49}$

A diversidade de espécies é de extrema importância para a manutenção dos processos ecológicos. Townsend et. al. ${ }^{50}$, após traçarem três cenários possíveis correlacionando riqueza de espécies e processos ecossistêmicos - um no qual há um aumento ou redundância de espécies, outro no qual o número de espécies permanece estável e um terceiro em que há perda de espécies -, chegam à conclusão de que, em qualquer dos casos, a perda da biodiversidade inviabilizaria os processos ecológicos. Ao questionar-se acerca de qual dos modelos estaria mais próximo da realidade e até que ponto poderia ser mantida a eficácia dos processos ecossistêmicos com a perda de algumas espécies, os autores afirmam que a única resposta disponível é que não se tem a menor idéia.

A ausência de elementos indicativos acerca dos efeitos advindos da perda da biodiversidade desafia a exegese dos princípios da prevenção e da precaução.

A constatação de que danos ambientais são de difícil reparação e muitas vezes não podem ser indenizados encontra-se na raiz dos princípios da prevenção e da precaução. Conforme avança a sociedade global de risco, medidas antecipatórias se fazem urgentes, dada a necessidade de se evitar catástrofes ambientais de grande potencial lesivo em decorrência das dificuldades técnicas e dos altíssimos custos a ser despendidos com a recuperação ou indenização de agressões ao meio ambiente. Dessa forma, nos dias atuais impõem-se como regra atitudes prevencionistas e precaucionistas.

Em relação a possíveis diferenças entre os princípios da prevenção e da precaução, alguns doutrinadores, dentre os quais Fiorillo ${ }^{51}$, referem os vocábulos como sinônimos. Leite ${ }^{52}$ entende os princípios da atuação preventiva (prevenção) e da precaução como irmãos, pertencentes à mesma família, lados opostos de uma mesma moeda considerada como o ponto de destaque da política ambiental, atuando na gestão antecipatória, inibitória e cautelar dos riscos ecológicos. O autor reconhece o caráter mais genérico e amplo da atuação preventiva em relação à precaução, mais específica e ligada ao momento inicial do exame do risco.

\footnotetext{
${ }^{49}$ PRIMACK, Richard B.; RODRIGUES, Efraim. Op. cit., p 82.

${ }^{50}$ TOWNSEND, Colin R.; BEGON, Michael; HARPER, John L. Fundamentos em ecologia. 2. ed. Trad. Gilson Rudinei Pires Moreira et. al. Porto Alegre: Artmed, 2006, p. 534-535.

${ }^{51}$ FIORILlO, Celso Antônio Pacheco. Curso de direito ambiental brasileiro. 7. ed. rev. e atual. São Paulo: Saraiva, 2006, p. 39-41.

${ }^{52}$ LEITE, José Rubens Morato. Sociedade de risco e estado. In: CANOTILHO, José Joaquim Gomes; LEITE, José Rubens Morato (orgs.). Direito constitucional ambiental brasileiro. Rio de Janeiro: Saraiva, 2007. p. 171-172.
} 
Balbinott ${ }^{53}$ os diferencia aduzindo encontrar-se o princípio da prevenção voltado à ação antecipada, através do diagnóstico dos riscos decorrentes de determinado empreendimento ou atividade, para depois avaliar a pertinência de sua instalação ou operacionalização e a necessidade de se adotar determinadas medidas que venham a impedir a ocorrência de danos ambientais. Já o princípio da precaução, na visão do autor:

[...] encontra espaço diante da incerteza científica, que não pode ser tida como justificativa para que igualmente sejam adotadas medidas visando evitar a degradação ambiental ou o risco de sua ocorrência. Acaba assim alterando o modo como as decisões têm sido tomadas até este momento histórico, baseadas na pretensa certeza conferida pela ciência, cuja ausência de respostas completas a todos os fenômenos faz com que tenhamos que decidir diante da incerteza, do risco. As escolhas a serem adotadas não possuem apenas conotação científica, sendo marcadas por um forte grau de politização e de compromisso ético-social.

Vencidas as noções gerais sobre os princípios em questão, passa-se à problematização destes em função da perda acentuada da biodiversidade.

Apesar de apontada como um dos grandes problemas ambientais hodiernos, quando comparada aos demais a perda da biodiversidade recebe menor atenção do que deveria, não somente em razão de seu estágio atual, de sua importância para o funcionamento dos ecossistemas e de seu valor para a humanidade, mas também em função de ser o elemento que melhor identifica a solidão do homem moderno no mundo.

Extinções em massa de espécies não são novidades na história do planeta. Primack et. al. ${ }^{54}$ afirmam que a Terra está passando pelo sétimo evento de megaextinção. O que diferencia a atual perda da biodiversidade - causada pelo homem das anteriores é sua velocidade. Townsend et. al. ${ }^{55}$ (2006, p. 516-517), comparando as estimativas atuais com a taxa histórica de extinção decorrente de fatores naturais, concluem que houve um acréscimo de 100-1000 vezes na taxa de extinção de aves e mamíferos em relação às extinções de fundo.

Além do quê, não se consegue estabelecer o número de espécies existentes na Terra. Begon et. al. ${ }^{56}$ informam que já foram denominadas cerca de 1,8 milhão

\footnotetext{
${ }^{53}$ BALBINOTT, André Luiz. Os desafios ambientais e o direito: regulação direta e instrumentos econômicos para a gestão ambiental. 2007. 165 f. Dissertação (Mestrado em Ciências Ambientais) Universidade Comunitária Regional de Chapecó, Chapecó, 2007, p. 23.

${ }^{54}$ PRIMACK, Richard B.; ROZZI, Ricardo; FEINSINGER, Peter; DIRZO, Rodolfo; MASSARDO, Francisca (orgs.). Fundamentos de conservación biológica: perspectivas latinoamericanas. México: Fondo de Cultura Econômica, 2001, p. 135.

${ }_{55}^{5}$ TOWNSEND, Colin R.; BEGON, Michael; HARPER, John L. Op. cit., p. 516-517.

${ }^{56}$ BEGON, Michael; TOWNSEND, Colin R.; HARPER, John L. Op. cit., p. 202.
} 
de espécies, mas o número real é muito maior. Dependendo dos métodos utilizados, as estimativas em relação ao número total de espécies variam de 3 a 30 milhões, ou mais. Dessa forma, na melhor das hipóteses conhece-se um pouco mais da metade das espécies que habitam o planeta.

Como proteger diante de tanta incerteza (número total de espécies)? Precaução? O que priorizar diante de tanta certeza (taxas atuais de extinção)? Prevenção? Como agir? Os dados apontados pelos estudiosos da conservação biológica demonstram a necessidade de, em nome da prevenção e da precaução, adotar-se medidas de revitalização de espécies ameaçadas de extinção e podem ajudar na definição de parâmetros precaucionais e preventivos.

\section{Serviços ecossistêmicos}

Além do valor intrínseco dos bens ambientais, os processos ecológicos prestam uma série de serviços que beneficia todos os organismos que vivem na Terra e são responsáveis pela manutenção da vida no planeta. Estes processos diretamente ou indiretamente apropriados denominam-se "serviços ecossistêmicos" e encontram-se relacionados com o valor da diversidade genética e de espécies, da produção, transformação e manutenção da energia e da ciclagem de nutrientes (ciclos biogeoquímicos).

O valor dos serviços ecossistêmicos serve de parâmetro para a análise dos princípios do poluidor-pagador e do usuário-pagador.

O princípio 16 da Declaração do Rio de Janeiro de 1992 fornece as bases conceituais do princípio do poluidor-pagador: "As autoridades nacionais deverão esforçar-se por promover a internalização dos custos ambientais e a utilização de instrumentos econômicos, tendo em conta o princípio de que o poluidor deverá, em princípio, suportar o custo da poluição, com o devido respeito pelo interesse público e sem distorcer o comércio e investimento".

Informa Prieur ${ }^{57}$ : "Este princípio é inspirado pela teoria econômica de acordo com a qual os custos sociais externos que acompanham a produção industrial devem ser internalizados, ou seja, tidos em conta pelos agentes econômicos nos seus custos de produção".

O princípio do poluidor-pagador cumpre, na lição de Derani ${ }^{58}$, uma dupla função: i) visa a internalização dos custos relativos externos de deterioração do meio ambiente, impondo ao utilizador de recursos naturais que possa causar um dano

\footnotetext{
${ }^{58}$ DERANI, Cristiane. Direito ambiental econômico. São Paulo: Max Limonad, 1997, p. 158-159.

${ }^{57}$ PRIEUR, Michel. Op. cit., p. 145.
} 
ambiental arcar com os custos relativos à sua diminuição ou afastamento - neste sentido o princípio adquire um caráter preventivo (Verursacherprinzip); ii) visa, também, a internalização das externalidades negativas decorrentes de processos produtivos que acabam sendo suportadas por toda a população, fazendo com que o utilizador de recursos naturais seja responsabilizado por elas - caráter reparatório (Verantwortungsprinzip).

A constatação de que os recursos naturais são apropriados de forma gratuita, passando a integrar o patrimônio de determinada pessoa em detrimento dos demais membros de uma comunidade localiza-se na base do princípio do usuário-pagador.

A questão que ora se impõe refere-se à mensuração monetária dos recursos ambientais em função de seus diversos valores, através de métodos estimativos estruturados a partir de aportes teóricos da economia do meio ambiente, disciplina cada vez mais presente em cursos de economia e que tem por escopo o estudo das externalidades negativas e a sua internalização, lançando mão, para tanto, da valoração monetária dos recursos ambientais.

Motta $^{59}$ realiza uma taxonomia do valor econômico dos recursos ambientais dividindo-os em dois grandes grupos, a partir de dois critérios: i) valor de uso do bem ambiental; ii) valor de não-uso dos recursos naturais.

No primeiro grupo (valor de uso) encontram-se os bens e serviços ambientais cuja valoração se dará em função de: i) ser apropriados diretamente e consumidos hoje (valor de uso direto - VUD); ii) constituir funções ecossistêmicas apropriadas indiretamente no presente (valor de uso indireto - VUI); e iii) que poderiam ser apropriados hoje mas que, por opção, são resguardados para utilização futura (valor de opção - VO).

No segundo grupo (valor de não-uso) encontram-se aqueles bens e serviços que, por questões morais, culturais, éticas ou altruísticas, não têm o valor atrelado a seu uso concreto ou potencial (valor de existência - VE).

O valor econômico dos recursos naturais (VERA) é o somatório dos valores de uso e não-uso, podendo ser levantado através dos seguintes métodos: i) métodos da função de produção - permitem observar o valor do recurso ambiental em razão de sua contribuição como insumo ou fator de produção de um produto qualquer; ii) métodos de mercado de bens substitutos - procuram estimar a variação da receita líquida de determinada atividade em razão do aumento dos custos para o seu desenvolvimento, levando em consideração a necessidade de se adotarem bens naturais substitutos em decorrência da diminuição ou perda de qualidade daqueles que vinham sendo utilizados para a produção de determinado bem ou serviço, dos custos

${ }^{59}$ MOTTA, Ronaldo Seroa da. Economia ambiental. Rio de Janeiro: FGV, 2006.

Revista Seqüência, nº 56, p. 123-150, jun. 2008. 
que seriam evitados caso não houvesse a necessidade de substituição de determinado insumo produtivo e ainda dos gastos de controle de determinada variável ambiental; iii) métodos de valor de opção - procuram apurar o valor atribuído a bens excluídos que seriam utilizados em um futuro próximo; ${ }^{60} \mathrm{e}$ iv) métodos de valor de não-uso ou valor de existência - levam em consideração o não-uso atual ou futuro por questões morais, culturais, éticas ou altruísticas. Os valores dos bens ou serviços podem ser estimados a partir de diversos parâmetros: disposição a pagar pela não-utilização do bem ou pela manutenção de uma espécie, valores gastos em viagens para apreciar determinada paisagem, valor hedônico de determinado bem etc. ${ }^{61}$

A abordagem perfunctória dos métodos de valoração ambiental foi realizada somente com o intuito de demonstrar a dependência do direito ambiental de outras áreas do conhecimento para a definição e efetivação dos princípios do poluidorpagador e usuário-pagador. Raciocínio semelhante é válido para os demais princípios abordados neste artigo.

Arremata-se concluindo que uma interpretação atualizada dos princípios do direito ambiental, que possibilite respostas às demandas ditadas pela sociedade de risco global, passa pela re-significação destes através dos postulados da ecologia natural e das demais ciências e saberes relacionados à vida na Terra. Pois a atualização do direito ambiental passa por uma abordagem que privilegie a análise multidisciplinar de seus princípios, instrumentos e institutos, cruzando-os com as demais disciplinas e saberes com quem deve comunicar-se. Em outra palavras, é mister que o direito ambiental se alicerce no saber ambiental, que ocupe o seu lugar de fronteira, de interface entre as diversas áreas do conhecimento.

\section{Referências}

ALIER, Joan Martinez; JUSMET, Jordi Roca. Economia ecológica y política ambiental. 2. ed. México: Fondo de Cultura Econômica, 2001.

ATLAN, Henri. Entre o cristal e a fumaça: ensaio sobre a organização do ser vivo. Rio de Janeiro: Zahar, 1992.

BALBINOTT, André Luiz. Os desafios ambientais e o direito: regulação direta e instrumentos econômicos para a gestão ambiental. 2007. 165 f. Dissertação (Mestrado em Ciências Ambientais) - Universidade Comunitária Regional de Chapecó, Chapecó, 2007.

\footnotetext{
${ }^{60}$ Ibidem, p. 18.

${ }^{61}$ ALIER, Joan Martinez; JUSMET, Jordi Roca. Op. cit., p. 241-250.
} 
BARRAL, Welber; FERREIRA, Gustavo Assed. Direito ambiental e desenvolvimento. In: BARRAL, Welber; PIMENTEL, Luiz Otávio (orgs.). Direito ambiental e desenvolvimento. Florianópolis: Boiteux, 2006, p. 13-45.

BEGON, Michael; TOWNSEND, Colin R.; HARPER, John L. Ecologia: de indivíduos a ecossistemas. 4. ed. Trad. Adriano Sanches Melo et al. Porto Alegre: Artmed, 2007.

BELLO FILHO, Ney de Barros. Teoria do direito e ecologia: apontamentos para um direito ambiental no século XXI. In: FERREIRA, Helini Sivini; LEITE, José Rubens Morato (orgs.). Estado de Direito Ambiental: tendências: aspectos constitucionais e diagnósticos. Rio de Janeiro: Forense, 2004, p. 71-108.

BENJAMIN, Antônio Herman. Direito constitucional ambiental brasileiro. In: CANOTILHO, José Joaquim Gomes; LEITE, José Rubens Morato (orgs.). Direito constitucional ambiental brasileiro. Rio de Janeiro: Saraiva, 2007. p. 57-130.

BRASIL. Constituição (1988). Constituição Federal, legislação administrativa, legislação ambiental. Nylson Paim de Abreu Filho (org.). 4. ed. Porto Alegre: Verbo Jurídico, 2006.

. Lei $\mathbf{n}^{\circ} \mathbf{6 . 9 3 8}$, de 31 de agosto de 1981. Constituição (1988).

Constituição Federal, legislação administrativa, legislação ambiental. Nylson Paim de Abreu Filho (org.). 4. ed. Porto Alegre: Verbo Jurídico, 2006.

Lei ${ }^{\circ}$ 9.985, de 18 de julho de 2000. Constituição Federal, Código Civil e Código de Processo Civil. Nylson Paim de Abreu Filho (org.). 6. ed. Porto Alegre: Verbo Jurídico, 2006.

DAJOS, Roger. Princípios de ecologia. 5. ed. Trad. Fátima Murad. Porto Alegre: Artmed, 2005.

DERANI, Cristiane. Direito ambiental econômico. São Paulo: Max Limonad, 1997.

DUARTE, Marise Costa de Souza. As novas exigências do direito ambiental. In: LEITE, José Rubens Morato; BELLO FILHO, Ney de Barros (orgs.). Direito ambiental contemporâneo. Barueri: Manole, 2004, p. 503-530.

FIORILLO, Celso Antônio Pacheco. Curso de direito ambiental brasileiro. 7. ed. rev. e atual. São Paulo: Saraiva, 2006.

FOLADORI, Guilhermo. Limites do desenvolvimento sustentável. Campinas: Unicamp, São Paulo: Imprensa Oficial, 2001.

LEITE, José Rubens Morato. Dano Ambiental: do individual ao coletivo extrapatrimonial. São Paulo: Revista dos Tribunais, 2000. 
; AYALA, Patryck de Araújo. Novas tendências e possibilidades do direito ambiental no Brasil. In: WOLKMER, Antônio Carlos; LEITE, José Rubens Morato (orgs.). Os novos direitos no Brasil: natureza e perspectivas. São Paulo: Saraiva, 2003, p. 181-292.

; Sociedade de risco e estado. In: CANOTILHO, José Joaquim Gomes; LEITE, José Rubens Morato (orgs.). Direito constitucional ambiental brasileiro. Rio de Janeiro: Saraiva, 2007. p. 130-204.

MARGALEF, Ramón. Ecologia. Barcelona: Omega, 2005.

MATURANA, Humberto. Biologia da autoconsciência. In: CAMPOS PELLANDA, Nize Maria; PELLANDA, Luis Ernesto Cabral (orgs.). Psicanálise hoje: uma revolução do olhar. Petrópolis: Vozes, 1996.

MONOD, Jacques. O acaso e a necessidade: ensaio sobre a filosofia natural da biologia moderna. 4. ed. Petrópolis: Vozes, 1989.

MONTIBELLER FILHO, Gilberto. O mito do desenvolvimento sustentável: meio ambiente e custos sociais no moderno sistema produtor de mercadorias. 2. ed. rev. Florianópolis: UFSC, 2004.

MOTTA, Ronaldo Seroa da. Economia ambiental. Rio de Janeiro: FGV, 2006. ODUM, Eugene P. Ecologia. Trad. Ricardo Iglesias Rios e Christopher J. Tribe. Rio de Janeiro: Guanabara Koogan, 1988.

; BARRETT, Gary W. Fundamentos de ecologia. Trad. Pégasus Sistemas e Soluções. São Paulo: Thomson Learning, 2007.

ONU. Declaração da Conferência da ONU sobre meio ambiente. Estocolmo. 1972. Janeiro. 1992.

. Declaração do Rio sobre ambiente e desenvolvimento. Rio de OST, François. A natureza à margem da lei: a ecologia à prova do direito. Lisboa: Instituto Piaget, 1997.

PIERRI, Naína. El proceso histórico y teórico que conduce a la propuesta del desarrollo sustentable. In: PIERRI, Naína; FOLADORI, Guilhermo (orgs.). ¿Sustentabilidad?: Desacuerdos sobre el desarrollo sustentable. Montevidéu: Trabajo y Capital, 2001, p. 59.

PRIEUR, Michel. Droit de l'environnement. 5. ed. Paris: Dalloz, 2004. PRIGOGINE, Ilya; STENGERS, Isabelle. A nova aliança: metamorfose da ciência. Trad. Miguel Faria e Maria Joaquina Machado Trincheira. Brasília: Universidade de Brasília, 1991. 
PRIMACK, Richard B.; RODRIGUES, Efraim. Biologia da conservação. Londrina: E. Rodrigues, 2001. ; ROZZI, Ricardo; FEINSINGER, Peter; DIRZO, Rodolfo; MASSARDO, Francisca (orgs.). Fundamentos de conservación biológica: perspectivas latinoamericanas. México: Fondo de Cultura Econômica, 2001. RICKLEFS, Robert E. A economia da natureza. 5. ed. Trad. Cecília Bueno, Pedro P. de Lima-e-Silva e Patrícia Moussinho. Rio de Janeiro: Guanabara Koogan, 2003.

ROCHA, Leonel Severo; CARVALHO, Delton Winter de. Policontextularidade e direito ambiental reflexivo. In: Revista Seqüência: estudos jurídicos e políticos n. 53. Florianópolis: Boiteux, 2006, p. 9-28.

SCHRÖDINGER, Erwin. O que é a vida? 2. ed. Trad. M. L. Pinheiro. Lisboa: Fragmentos, 1989.

TOWNSEND, Colin R.; BEGON, Michael; HARPER, John L. Fundamentos em ecologia. 2. ed. Trad. Gilson Rudinei Pires Moreira et. al. Porto Alegre: Artmed, 2006. 